\title{
EDITORIAL
}

D) Check for updates

\section{Year 2 in numbers}

Closing the second volume of Nature Reviews Physics we thank our authors, readers and referees.

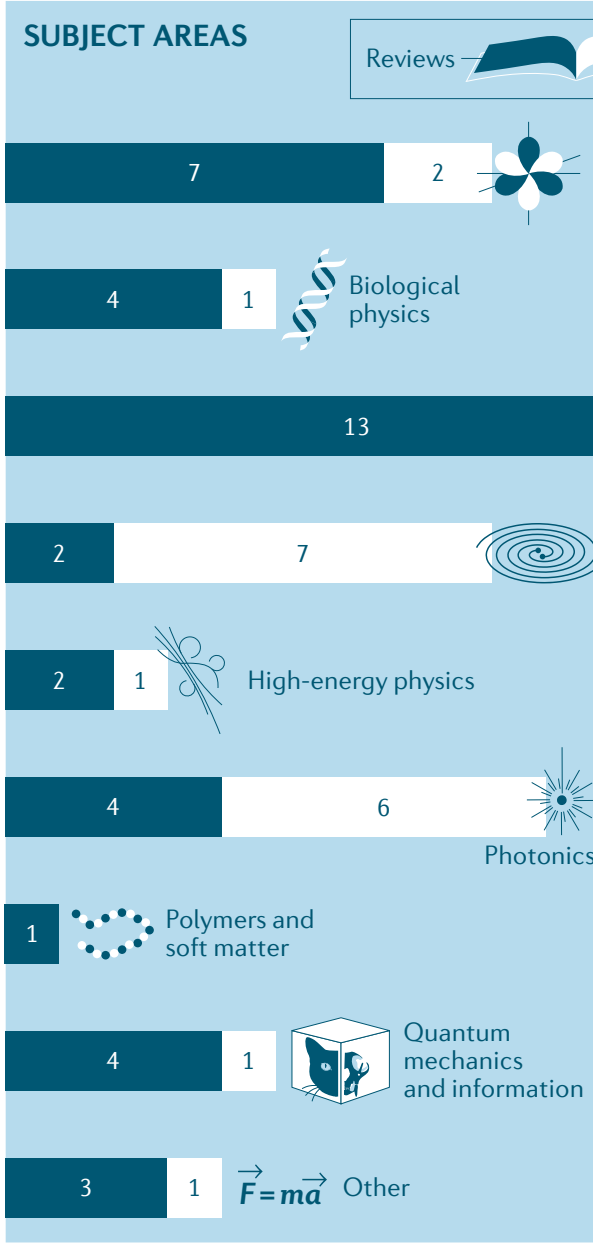

Atomic, molecular and optical

News \& Comment

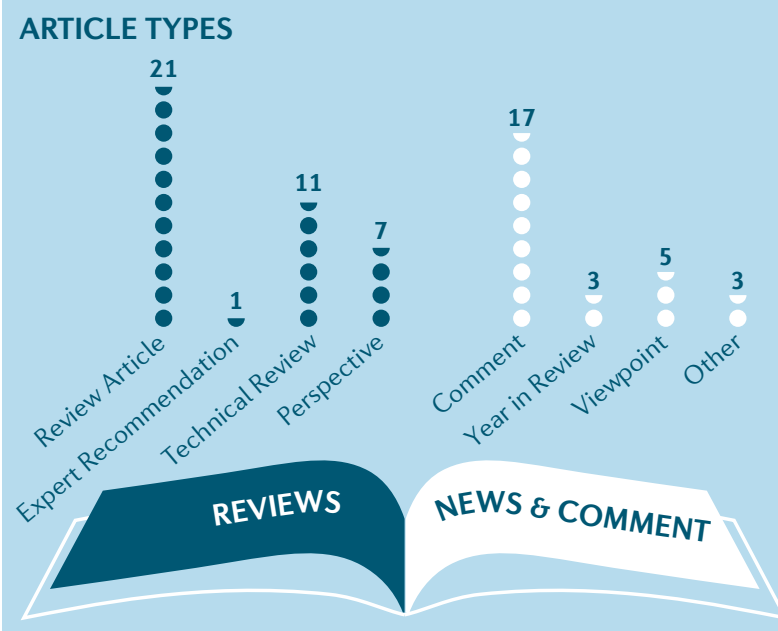

Gravitation,

cosmology

Condensed matter and materials physics
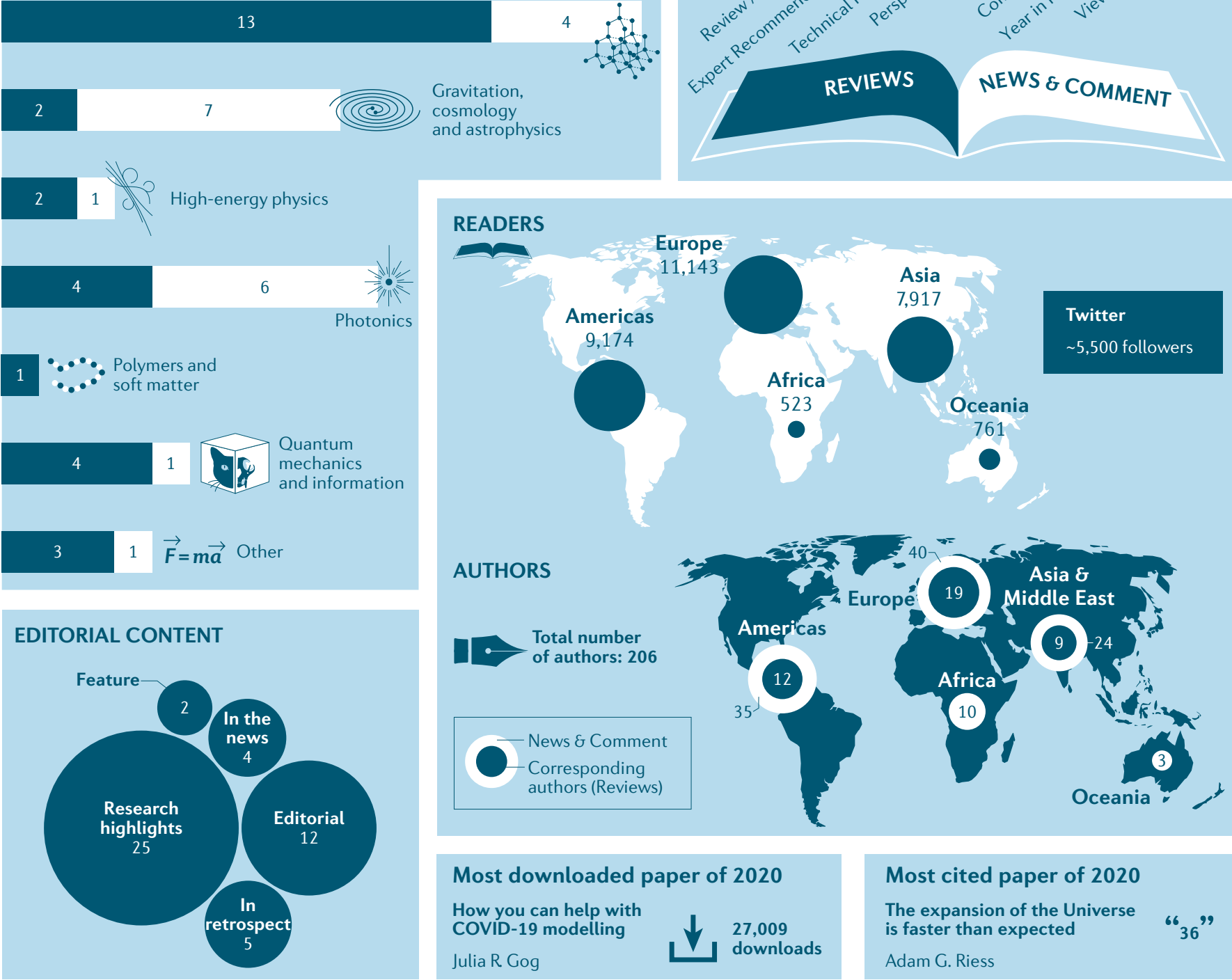

Most downloaded paper of 2020

How you can help with COVID-19 modelling $\forall \begin{aligned} & 27,009 \\ & \text { downloads }\end{aligned}$

Most cited paper of 2020

The expansion of the Universe is faster than expected Adam G. Riess
Data sources

The reader data was obtained using Google analytics. The author data is based on the primary institutional affiliation. 